\title{
Series and Parallel Arc Fault Detection in Electrical Buildings Based on Discrete Wavelet Theory
}

\author{
Elaf Abed Saeed*, Khalid M. Abdulhassan, Osama Y. K. Al-Atbee \\ Electrical Engineering Department, University of Basrah, Basrah, Iraq
}

\author{
Correspondence \\ *Elaf Abed Saeed \\ Electrical Engineering Department \\ University of Basrah, Basrah, Iraq. \\ Email: elaphabd96@gmail.com
}

\begin{abstract}
Electrical issues such as old wires and faulty connections are the most common causes of arc faults. Arc faults cause electrical fires by generating high temperatures and discharging molten metal. Every year, such fires cause a considerable deal of destruction and loss. This paper proposes a new method for detecting residential series and parallel arc faults. A simulation model for the arc is employed to simulate the arc faults in series and parallel circuits. The fault features are then retrieved using a signal processing approach called Discrete Wavelet Transform (DWT) designed in MATLAB/Simulink based on the fault detection algorithm. Then $\mathrm{db2}$ and one level were found appropriate mother and level of wavelet transform for extracting arc-fault features. MATLAB Simulink was used to build and simulate the arc-fault model.
\end{abstract}

KEYWORDS: arc fault, discrete wavelet transform (DWT), parallel arc fault model, series arc fault model.

\section{INTRODUCTION}

Electrical fires are one of the deadliest and most common 21st-century risks. According to Fire Safe Europe, a European organization dedicated to building fire safety, 200000 fires are reported in Europe each year, with buildings accounting for $90 \%$ of all incidents in the EU. Every year, fire kills 4000 people in Europe, an average of 11 persons per day. Every year, 7000 individuals are admitted to hospitals throughout Europe as a result of severe fire injuries. [1]. So, one of the reasons is the arc fault. Arc faults can be classified into two types: series and parallel. The first form, which is the most common, happens when a single power conductor fails. The parallel arc fault occurs between the neutral/ground and phase conductor.

There are many different techniques that are used to detect the arc fault, such as Arc fault circuit interrupter (AFCI), Short-Time Fourier Transform method, and Fast Fourier Transform, Arc fault circuit interrupter AFCI was presented in 1998. This presentation provides context for the AFCI's intended role of detecting arcs that may contribute to fire triggers. It compares the AFCI to overcurrent protective equipment and ground-fault circuit interrupters; available AFCI devices have ratings of 15 and $20 \mathrm{~A}$ at 120 V. Devices for industrial and commercial uses are not yet available. However, as long as the computer is geared to the load, the technology lends itself very well to these requirements [2], Series Arc Fault Detection and
Implementation Based on The Short-time Fourier Transform at 2010. Using the STFT, this approach introduces a significant sequence arc fault detection method based on three parameters to the $50 \mathrm{~Hz}$ fundamental variable, even and odd harmonics (STFT). Experiment findings with a sequence of arc fault prediction tests and unintended tripping tests partly validate the detection algorithm's feasibility [3]. In addition, introduced Real Time Series AC Arc Fault Detection Based on Fast Fourier Transform. At 2018 Real Time Series AC Arc Fault Detection Using the Fast Fourier Transform was implemented. The spectrum from the FFT measurement can be used to recognize current interference and calculate the arcing fault condition on the device using this tool. However, this approach is not applicable to power-supply current that contains disruptions. The picket fence effect (resolution bias error) is another issue with FFT, which occurs when a signal produces harmonics that are not an integral multiple of the resolution frequency [4].

This paper builds a suitable Simulink of series and parallel arc fault based on the MATLAB/Simulink with the arc gap energy-balance theory. The wavelet transform was used to extract the transient information of the arc current signal. And then, the singularity of the fault signal is analyzed to determine the fault moment. The simulation results show that this model can reflect the characteristics of actual series and parallel fault effectively. 


\section{Series ANd Parallel Arc Fault Model}

Two types of arc faults exist, the series and the parallel arc fault. The first model type is shown in Fig. 1 (a). It is the most common fault type. It happens when a single power conductor fails. The maximum arc current is therefore limited by the load current owing to the connection in series, which is significantly less than the CB current rating and, thus, the arc current may or may not generate enough heat to start a fire, depending on the load. [5].

Figure1 (b) shows the parallel arc fault. When the insulator is degraded by mechanical, temperature stress, or aging, it develops between the neutral/ground and phase conductor [6]. In this situation, the high-impedance arc melts and carbonizes the insulator first, followed by the lowimpedance current route. The trail forms due to extreme heat and, if left unattended, it might start a fire.
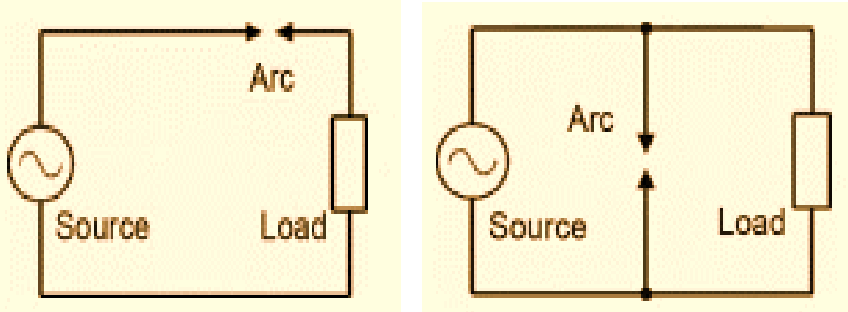

Fig. 1 (a): Series arc-fault.

(b): Parallel arc fault.

\section{A. Arc mathematical model}

The arc fault is a self-sustaining electrical discharge in conductive ionized gas [7], with circuit operation conditions limiting the maximum current. Arc may simply shorten the life of electrical devices, or become hazardous (for example, an electrical wire) and result in dramatic events such as fires and explosions. The arc fault carries discontinuous, nonlinear, and no sinusoidal characteristics.

Several models was builds to describe its behavior. Among them, the most popular is Cassie (used for studying the arc at high current and high plasma temperature conditions) and Mayr's arc model [8]. The latter maintains a constant arc diameter and power loss and represents arc conductance around zero current. This model is excellent for arc fault modeling in residential and office wiring since it works well for a low currents (tens of Amperes). Mayr arc model was based on energy balance theory, accordingly Mayr's arc-fault model expression [9]:

Where:

$$
\frac{d q}{d t}=e \times i-P_{\text {loss }}
$$

$\frac{d q}{d t}$ : storing energy changes per unit arc length.

$e \times \mathrm{i}$ : input power per unit arc length.

i: arc current.

e: electric intensity in arc column.

$\mathrm{P}_{\text {loss: }}$ power loss per unit arc length.
Because arc resistance value is very small, therefore the model can be expressed as the form of conductance [10].

$$
\begin{gathered}
g=\frac{1}{R}=\frac{i}{u}=F(q(t)) \\
\frac{d g}{d t}=\frac{d}{d t}\left(\frac{1}{R}\right)=\frac{d F(q)}{d q} \times \frac{d q}{d t}=(e \times i) \times \frac{d F(q)}{d q}
\end{gathered}
$$

For Mayr's arc model, the differential equation given by:

$$
\begin{gathered}
F(q)=k \times e^{q / q 0} \\
\frac{d g}{d t}=(e \times i) \times \frac{k}{q 0} \times e^{q / q 0} \\
\frac{d g}{d t}=\left(e \times i-P_{\text {loss }}\right) \times \frac{1}{q 0} \times F(q) \\
\frac{d g}{d t}=\left(e \times i-P_{\text {loss }}\right) \times \frac{g}{q 0} \\
\frac{1}{g} \times \frac{d g}{d t}=\frac{P_{\text {loss }}}{q 0} \times\left(\left(\frac{e \times i}{P_{\text {loss }}}\right)-1\right) \\
\text { Let } T=\frac{q_{0}}{P_{\text {loss }}} \quad \\
\frac{1}{g} \times \frac{d g}{d t}=\frac{1}{T} \times\left(\left(\frac{e \times i}{P_{\text {loss }}}\right)-1\right) \\
\frac{1}{g} \times \frac{d g}{d t}=\frac{1}{T} \times\left(\left(\frac{L \times e \times i}{L \times P_{\text {loss }}}\right)-1\right) \\
\frac{1}{g} \times \frac{d g}{d t}=\frac{1}{T} \times\left(\left(\frac{u \times i}{P_{0}}\right)-1\right)
\end{gathered}
$$

Where:

u: arc voltage, $u=L \times e$

$P_{0}$ : Power loss in arc column, $P_{0}=L \times P_{\text {loss }}=u_{c}{ }^{2} \times g$

$u_{c}$ : arc voltage constant

$\mathrm{g}$ : arc conductance

$$
\begin{gathered}
\frac{1}{g} \times \frac{d g}{d t}=\frac{1}{T} \times\left(\left(\frac{u \times i}{u_{c}^{2} \times g}\right)-1\right) \\
i=u \times g \\
\frac{1}{g} \times \frac{d g}{d t}=\frac{1}{T} \times\left(\left(\frac{u^{2}}{u_{c}^{2}}\right)-1\right) \\
\frac{d \ln g}{d t}=\frac{1}{T} \times\left(\left(\frac{u^{2}}{u_{c}^{2}}\right)-1\right)
\end{gathered}
$$

\section{B. Model parameters}

\section{(1) Determination of T}

T: reflects the rising velocity of arc voltage in the arc volt ampere Characteristic curve, and can be expressed as below:

Where:

$$
T=\frac{\alpha \times I_{p}}{L_{p}}
$$

Ip: is the peak current in the arc volt-ampere characteristic curvet. $I_{P}=25 \mathrm{~A}$

Alpha is the empirical value [9], take $\alpha=2.9 \times 10^{-5}$

$\mathrm{L}_{\mathrm{p}}$ : is the arc length which is approximate-constant [9].

$L_{p}=2 m m$ 
(2) Determination of $u_{c}$

A large number of experimental studies have shown that voltage drop per unit length along the main arc column is independent of the arc current. It is a constant, so this voltage constant is expressed below [9]:

$$
u_{c}=25 \times L_{p}
$$

\section{Arc FAult Simulation AND ANAlysis}

\section{A. Series arc simulation analysis}

In MATLAB/Simulink environment, it is established simulation circuit model for testing the effectiveness of the arc. In this case, there are the mainly arc simulation model parameters: power supply voltage $311 \mathrm{v}$, frequency $\mathrm{f}=50 \mathrm{~Hz}$. The simulation time ranges from 0 to 0.4 seconds, after which an arc current is generated by using Controlled Current Source block and measured using the AM1 block. The VM1 block calculates the voltage across the arc, and $R_{\text {load }}=5 \Omega$ represents load resistance (constants resistive load is assumed).

The differential equation editor (DEE) block is used to described Mayr arc model as shown in Fig.2.this block is also calculating the arc current $i_{\text {out }}$ [9]:

$g_{0}=1 e^{4} \mathrm{sm}$

$$
\begin{gathered}
i_{\text {out }}=e^{x} \times u \\
x_{0}=\log g_{0}
\end{gathered}
$$

Where: $g_{0}$ is the initial condition (initial arc conductivity). The user defined function is used to build the arc fault, so when the voltage source reach to a certain value the arc initiated, the MATLAB/Simulink model are shown in from Fig.3.

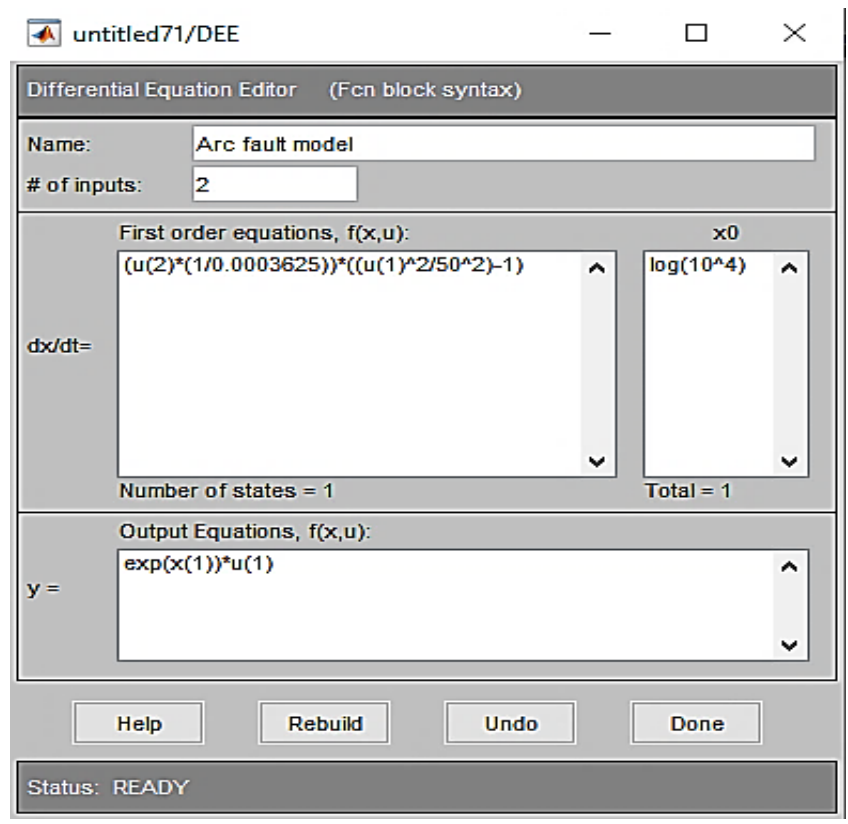

Fig. 2: DEE of Mayr arc model in MATLAB.

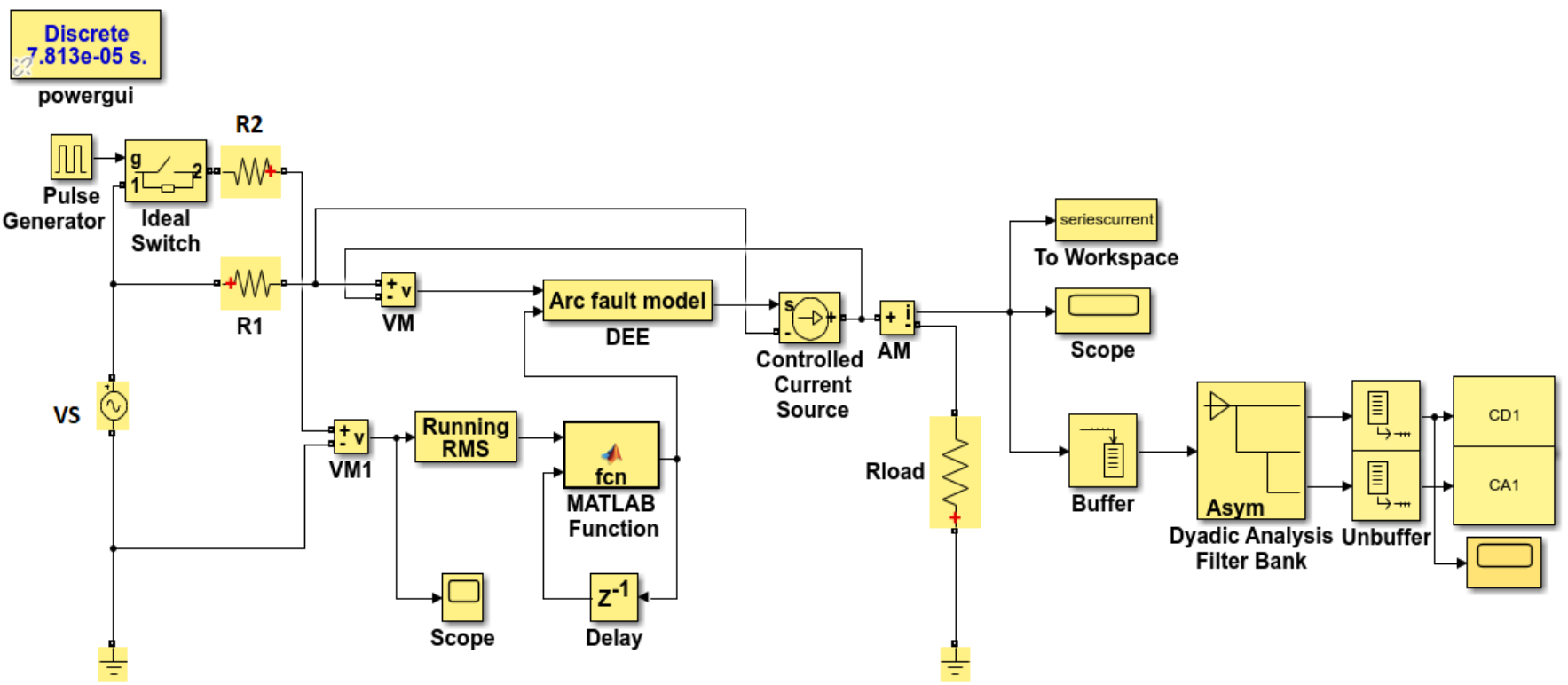

Fig. 3: Series arc fault simulation model. 


\section{B. Parallel arc simulation analysis}

In the parallel arc model, the simulation analysis is the same as the series arc fault analysis with the same model parameters, however the difference the arc is controlled by using unit step function, and arc start time is $0.03 \mathrm{~s}$, the load is short circuit for parallel arc fault [11], the Simulation model are shown in Fig. 4.

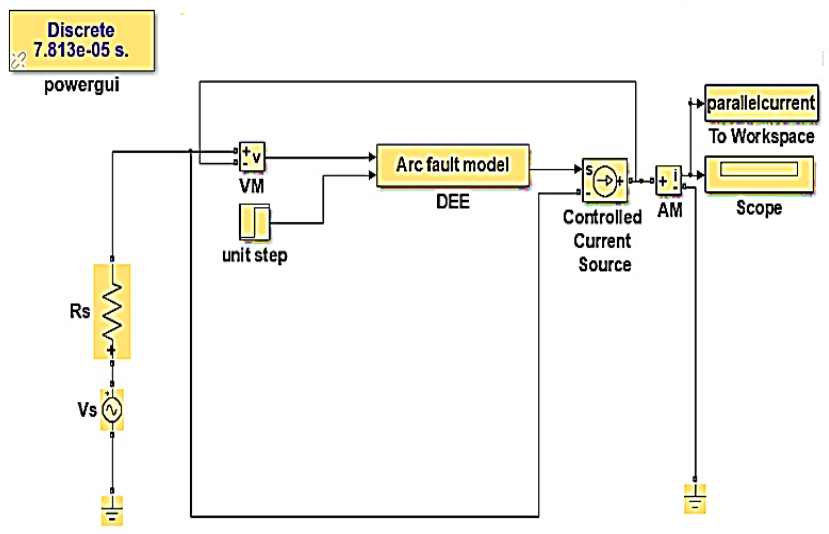

Fig. 4: Parallel arc fault simulation model.

The simulation models of the series and the parallel arc fault are shown in Fig. 3. and Fig. 4 respectively. With model parameters, the simulation of arc current waveforms is shown in Fig. 5 and Fig. 6.

Figure 5 shows the series arc fault, and it can be observed from this figure that when the voltage reaches a certain value $(220 \mathrm{v})$, then the arc is initiated.

Figure 6 shows the parallel arc current simulation result with high current due to a short circuit of load.

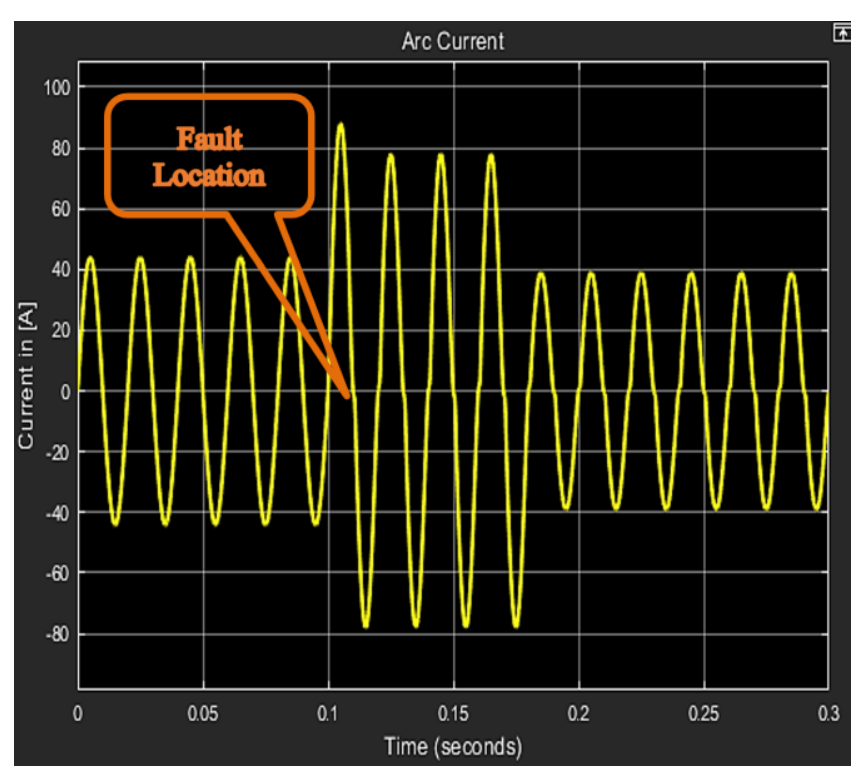

Fig. 5: Series arc current waveform.

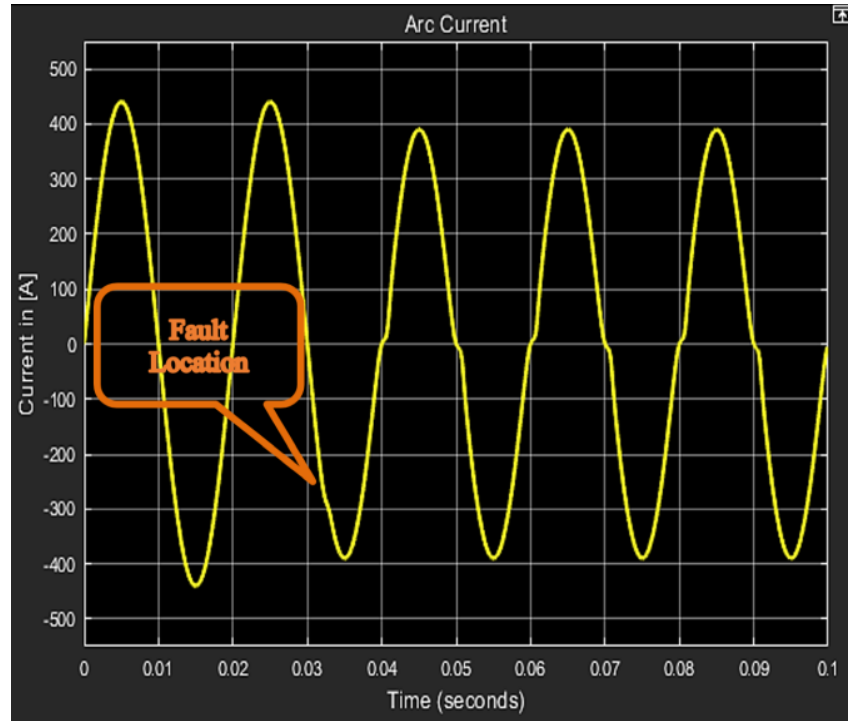

Fig. 6: Parallel arc current waveform.

These figures of series and parallel arc fault show the arc current waveform similar to a sine wave. Still, it changes slowly in zero-current area, which is characterized 'zero rest and it is also called (flat shoulders) signed with circle in Fig.5. The value of current is very close to zero in the period presented above. It declines before the current of over-zero but changes slowly in the points over-zero.

\section{WAVELET DETECTION}

The series and parallel arc voltage and current waveforms have a significant mutation and have a great singularity in the fault time when a single-phase ground fault occurs. It can extract the fault information from the rich transient waveforms and then determine the fault moment.

Fourier transform is a basic tool for studying the singularity of the function. However, due to the lack of spatial locality, it can only determine the overall nature of the singularity, and it is difficult to determine the distribution of their singular points in space [12],[13]. To overcome these drawbacks of Fourier transform, the wavelet analysis is effectively used to localized the arc moment.

Since the CWT will provide quite a redundancy of data due to taking into account every possible scale and shift steps, it turns out that if these steps are chosen based on a dyadic basis, then the analysis will be more efficient and space-saving [14],15]. This idea has been applied within the discrete wavelet transform (DWT), which is a powerful practical filtering technique by which fast wavelet transformation can be performed.

Signal analysis applications, as seen in a previous subsection, may require the low-frequency constituents of the signal. Other applications may require high-frequency ones. It is for that reason, the conventions of approximations and details are usually common to the DWT. 
Approximations represent the low-frequency large-scale constituents of the signal, whereas details represent the high-frequency small-scale signal constituents [14].

The DWT produces the approximations and details of signals utilizing a respective set of low and high pass filters. The existence of such a set of filters is dependent on two types of functions which are the scaling function and the wavelet function that are specific to certain types of mother wavelets [14],[15].

The iterative process of analyzing the signal within the set of DWT filters is called the Multi-Resolution Analysis (MRA). At the first decomposition stage, the signal enters the low pass filter (LPF) specific to a certain mother wavelet scaling function. The approximation coefficients (CA) will be obtained after the convolution of signal samples with the transfer function coefficients of such a filter and downsampling by 2 [14],16].

In order to obtain the detail coefficients (CD) of the signal at the decomposition first stage, it must be entered into a high pass FIR filter (HPF) specific to the wavelet function and having its samples convolved with the filter transfer function coefficients then downsampled by 2 .

At the second decomposition stage, the approximation coefficients obtained at the first stage will be treated in the same way as having the input signal treated to obtain the second stage approximation and detail coefficients. The MRA is shown in Fig.7, in which a signal of 1000 samples is entered, and out of which the coefficients have emerged. [14]. The mother wavelet $\mathrm{db} 2$ and the associated FIR filters are shown in Fig. 8. There are several families of wavelets shown in Fig. 9.

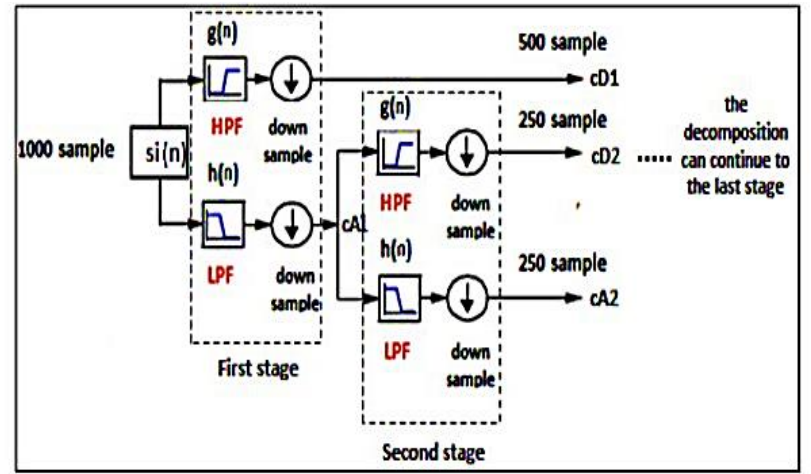

Fig. 7: MRA analysis.
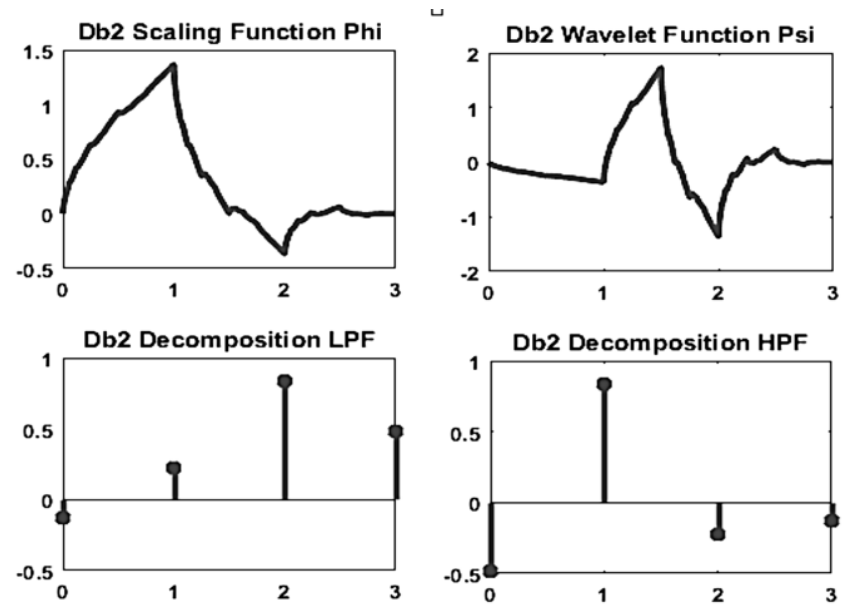

Fig. 8: Scaling and wavelet functions of Db2 mother wavelet and the associated FIR filters.
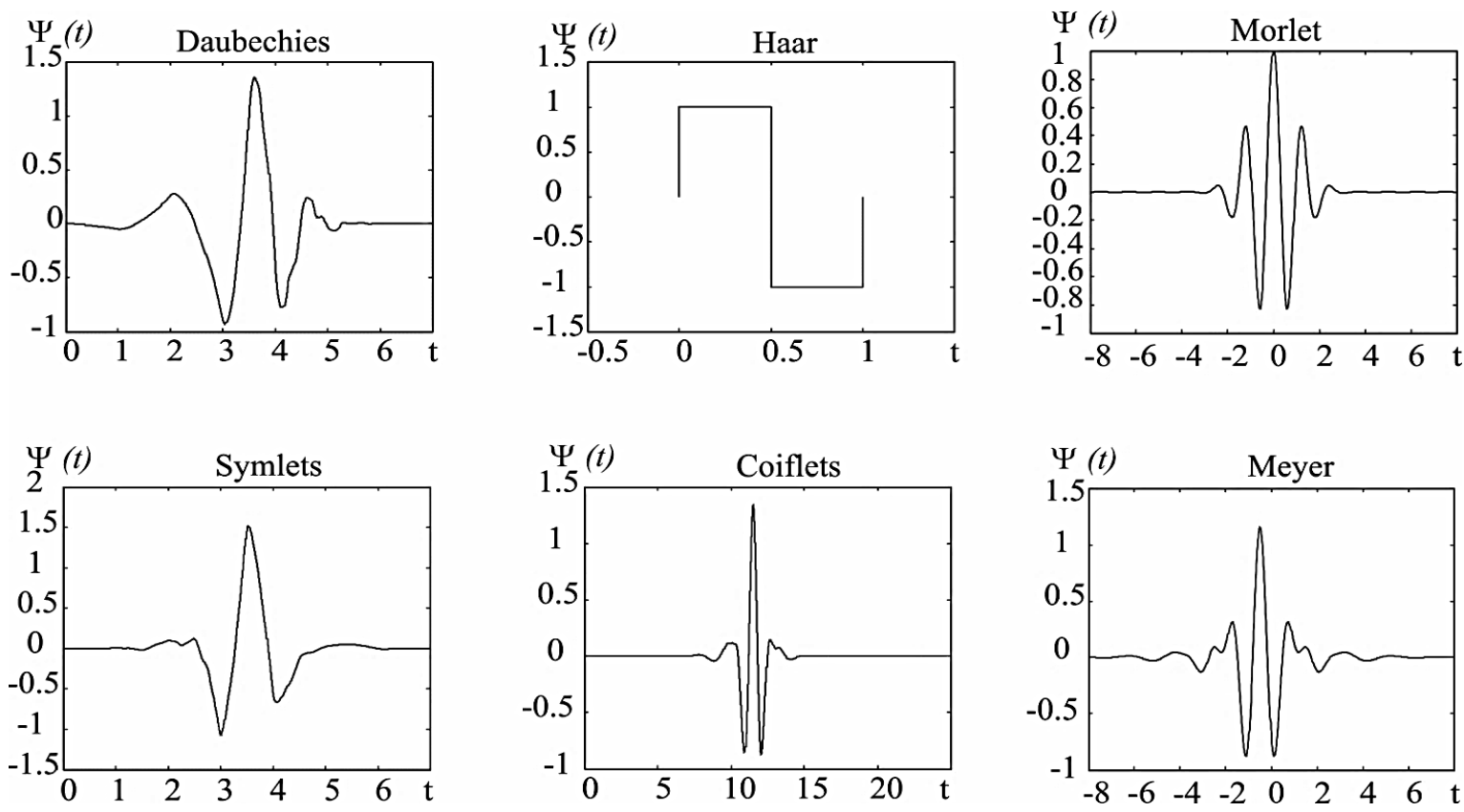

Fig. 9: Several families of wavelet transform. 


\section{SiMULATION RESULT}

This section presents simulation results for series and parallel arc fault with arc fault detection.

The following cases will show the Db2 three-stage approximation and detail coefficients as resultants from the series current and parallel related DWT analysis where cA1 and $\mathrm{cD} 1$ denote the approximation and detail coefficients obtained at the first stage of DWT decompositions. So here adopts the $\mathrm{db} 2$ wavelet, analyzes arc voltage and current waveforms in one-dimensional multi-scale. It is decomposed into two dimensions; fault occurs at $0.03 \mathrm{~s}$. Because the arc is a pure nonlinear resistance, the arc voltage, and current cross the zero at the same time.

Through the above descriptions, MATLAB/Simulink wavelet transform and simulation results of arc current waveforms can effectively determine the arc fault that occurred. In this paper, Daubechies' family of wavelets is the preferred family because of their high number of vanishing moments, making them capable of representing complex high degree polynomials and has the least number of average errors. Therefore, this thesis adopts the $\mathrm{db} 2$ wavelet, analyzes arc voltage and current waveforms in a one-dimensional multi-scale. It is decomposed into two dimensions; fault occurs at $0.03 \mathrm{~s}$. Because the arc is a pure nonlinear resistance, the arc voltage, and current cross the zero at the same time. Through the above descriptions, MATLAB/Simulink wavelet transform and simulation results of arc current waveforms can effectively determine the arc fault that occurred.

The simulation result with wavelet detection model of series and parallel arc fault with MATLAB/Simulink and use dyadic filter bank block to build the wavelet detection. This model is an online simulation by using buffer block from the DSP system toolbox shown in Figs.10 and 11. the simulation results of series and parallel arc fault with wavelet detection are shown in Figs. 12 and 13.

The simulation result with wavelet detection model of series and parallel arc fault with MATLAB/Simulink and use dyadic filter bank block to build the wavelet detection. This model is online simulation by using buffer block from DSP system toolbox shown in Figs. 9 and 10. the simulation results of series and parallel arc fault with wavelet detection are shown in Figs. 11 and 12.

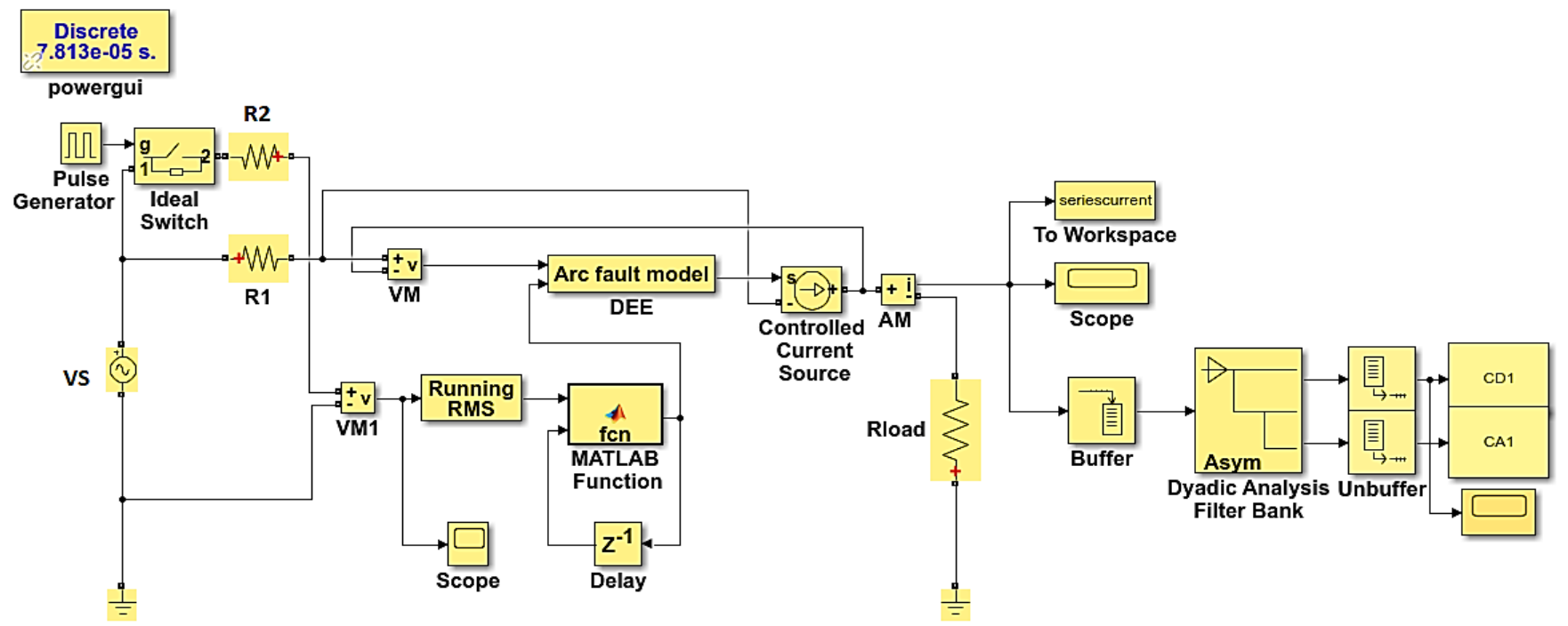

Fig. 10: Series arc fault with wavelet detection simulation model.

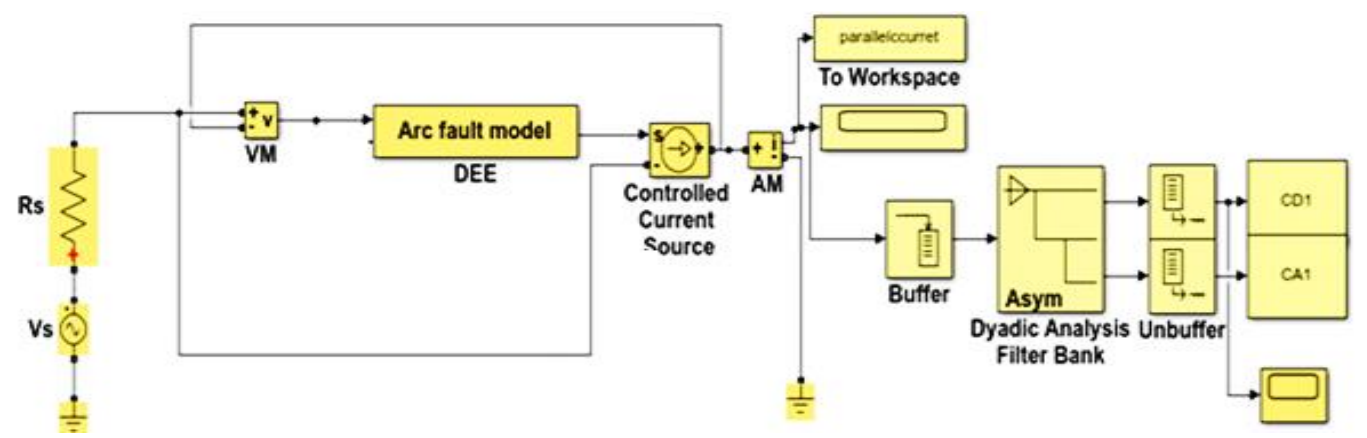

Fig. 11: Parallel arc fault with wavelet detection simulation model. 


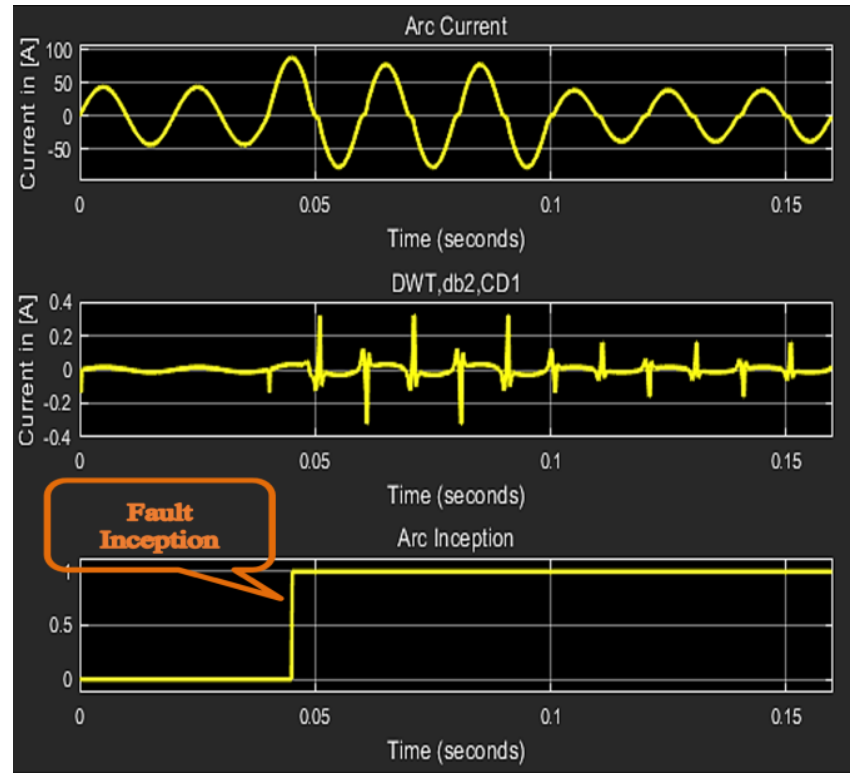

Fig. 12: Series arc fault feature extraction using DWT and $\mathrm{db} 2$.

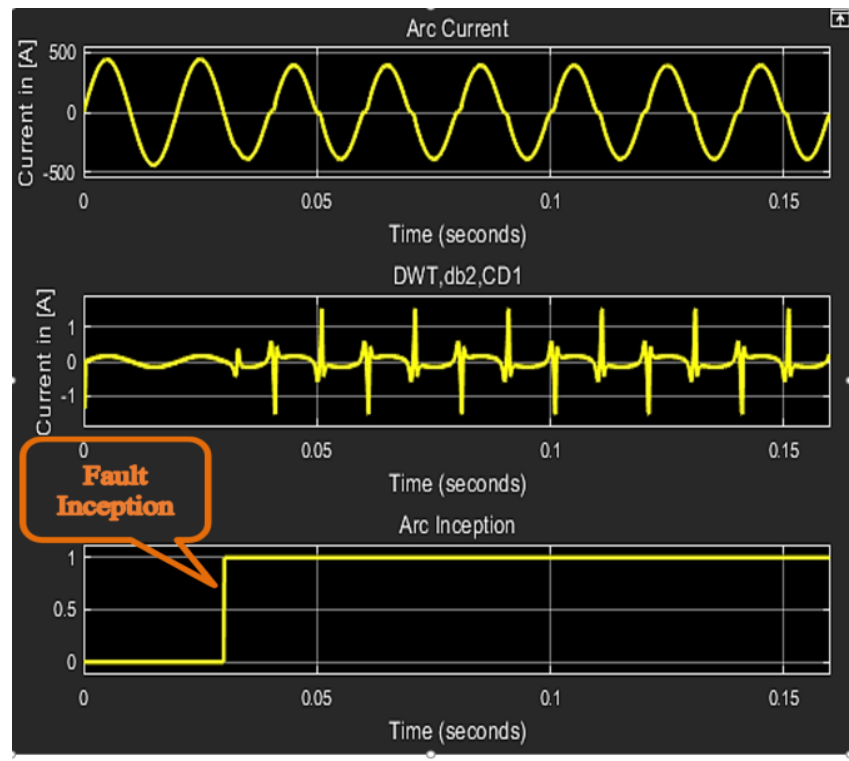

Fig. 13: Parallel arc fault feature extraction using DWT and $\mathrm{db} 2$.

\section{CONCLUSION}

This paper focused on series and parallel arc faults detection. A new MATLAB-based method for identifying residential series and parallel arc faults was provided, as well as a quick and reliable arc simulation model. The results reveal that this model is capable of accurately reflecting the characteristics of real-world series and parallel arc faults. This study shows the current and voltage waveforms of arc failures in circuits with completely resistive loads. By using wavelet transform analysis arc current waveform, it can effectively determine the arc fault moment.

\section{CONFLICT OF INTEREST} article.

The authors have no conflict of relevant interest to this

\section{REFERENCES}

[1] Fire Safe Europe, FSEU publications, 2019, https://firesafeeurope.eu/fseupublications/, online, accessed: 11.05.2019.

[2] G. D. Gregory and G. W. Scott, "The arc-fault circuit interrupter: an emerging product," in IEEE Transactions on Industry Applications, vol. 34, no. 5, pp. 928-933, Sept.-Oct. 1998, doi: 10.1109/28.720431.

[3] H. Cheng, X. Chen, F. Liu and C. Wang, "Series Arc Fault Detection and Implementation Based on the Shorttime Fourier Transform," 2010 Asia-Pacific Power and Energy Engineering Conference, Chengdu, China, 2010, pp. 1-4, doi: 10.1109/APPEEC.2010.

[4] M. H. Riza Alvy Syafi'i, E. Prasetyono, M. K. Khafidli, D. O. Anggriawan and A. Tjahjono, "Real Time Series DC Arc Fault Detection Based on Fast Fourier Transform," 2018 International Electronics Symposium on Engineering Technology and Applications (IES-ETA), Bali, Indonesia, 2018, pp. 25-30, doi: 10.1109/ELECSYM.2018.8615525.

[5] M. Naidu, T. J. Schoepf and S. Gopalakrishnan, "Arc fault detection scheme for 42-V automotive DC networks using current shunt," in IEEE Transactions on Power Electronics, vol. 21, no. 3, pp. 633-639, May 2006, doi: 10.1109/TPEL.2006.872385.

[6] N. Zamanan, J. Sykulski, and A. K. Al-Othman, "Arcing high impedance fault detection using real coded genetic algorithm," Conference: Third IASTED Asian Conference Power and Energy Systems, pp. 197203, 2007.

[7] I. Khan and M. Critchley, "Arc fault detector," 2000, vol. 25, no. 3, pp. 1-4. [Online]. Available: http://ebookbrowse.com/arc-fault-detector-paper-pdf$\mathrm{d} 245318580$.

[8] J. L. Guardado, S. G. Maximov, E. Melgoza, J. L. Naredo and P. Moreno, "An improved arc model before current zero based on the combined Mayr and Cassie arc models," in IEEE Transactions on Power Delivery, vol. 20, no. 1, pp. 138-142, Jan. 2005, doi: 10.1109/TPWRD.2004.837814.

[9] Q. Yin and R. Ding, "Review of Arc Models in Distribution Networks," matec web of conferences 61, 02016 (2016) DOI: 10.1051/MATCE.

[10] K. Koziy, B. Gou and J. Aslakson, "A Low-Cost PowerQuality Meter with Series Arc-Fault Detection Capability for Smart Grid," in IEEE Transactions on Power Delivery, vol. 28, no. 3, pp. 1584-1591, July 2013, doi: 10.1109/TPWRD.2013.2251753.

[11] R. Yu et al., "Modeling and simulation analysis of single-phase arc grounding fault based on MATLAB," Proceedings of $2011 \quad$ International Conference on Electronic \& Mechanical Engineering and 
Information Technology, Harbin, China, 2011, pp. $4607-$ 4610, doi: 10.1109/EMEIT.2011.6024001.

[12] ZHANG Zhao-Ning, MAO Peng. "Singularity detection of fault transient signals in power system with wavelet transforms," Relay, vol. 28 , no. 4, pp. 24-27, 2000.

[13] Wavelet Toolbox User's Guide for MATLAB, Version 1, MathWorks 2009.

[14] Sadiq I. Hassan, Adil A. Obed, and Khalid M. AbdulHassan, "Practical implementation for stator faults Protection and diagnosis in 3-ph IM based on WPT and neural network," The International Journal of Engineering and Science (IJES), Vol. 5, pp. 52-67, 2016.

[15] Michel Misti, Yves Misti, "Georges Oppenheim, and Jean-Michel Poggi, "Wavelet Toolbox, "User 's Guide, Math Works, July 2004.

[16] David C. Robertson, Octavia I. Camps, Jeffrey S. Mayer, and William B. Gish, "Wavelets and Electromagnetic Power System Transients," IEEE Transactions on Power Delivery, Vol. 11, No. 2, pp. 10501057, April 1996. 